\title{
Qualidade de sementes de tomate sob estágios de maturidade fisiológica de frutos e períodos de fermentação das sementes
}

\author{
Tomato seed quality under physiological fruit maturity stages and seed fermentation periods \\ Calidad de las semillas de tomate en etapas fisiológicas de madurez de frutos y periodos de
} fermentación de semillas

Recebido: 13/01/2022 | Revisado: 17/01/2022 | Aceito: 12/02/2022 | Publicado: 18/02/2022

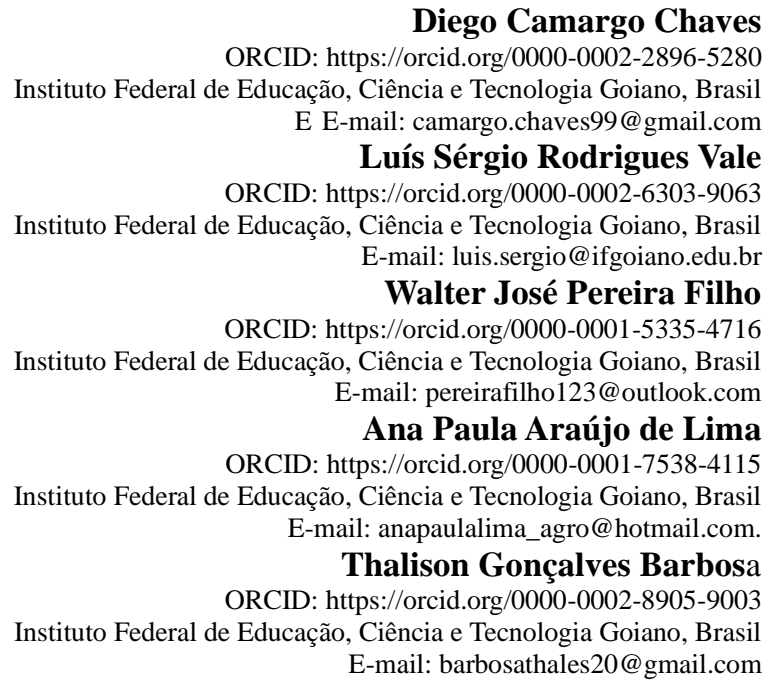

\section{Resumo}

$\mathrm{O}$ tomateiro apresenta maturidade fisiológica desuniforme dos frutos o que é um dos principais problemas na produção. Para retirada da mucilagem da semente do tomate podem ser utilizados vários métodos dentre eles se destaca a fermentação natural. Objetivou-se avaliar a qualidade de sementes de tomate sob diferentes estágios de maturidade fisiológica de frutos e períodos de fermentação. Foi utilizado o delineamento inteiramente casualizado em esquema fatorial $2 \times 6$. Os tratamentos foram 2 estágios de maturidade de frutos na colheita: maturidade média e maturidade total e seis períodos de fermentação após a extração das sementes: $0,2,4,6,8$ e 10 dias. As variáveis analisadas foram: teste padrão de germinação, emergência em campo, grau de umidade e massa seca de plântulas. $\mathrm{O}$ estágio de colheita de tomate de maturidade total de frutos apresentou melhores resultados para a qualidade de sementes. O período de fermentação com seis dias após a extração das sementes proporcionou melhores resultados para o vigor das sementes.

Palavras-chave: Germinação; Métodos de fermentação; Mucilagem; Saladete; Vigor.

\begin{abstract}
The tomato has an uneven physiological maturity of the fruit, which is one of the main problems in production. To remove mucilage from the tomato seed, several methods can be used, including natural fermentation. The aim of this study was to evaluate the quality of tomato seeds under different physiological maturity stages of fruits and fermentation periods. A completely randomized design in a $2 \times 6$ factorial scheme was used. The treatments were 2 stages of fruit maturity at harvest: medium maturity and full maturity and six fermentation periods after seed extraction: $0,2,4,6,8$ and 10 days. The variables analyzed were: standard germination test, field emergence, moisture content and seedling dry mass. The tomato harvest stage of full fruit maturity showed better results for seed quality. The six-day fermentation period after seed extraction provided better results for seed vigor.
\end{abstract}

Keywords: Germination; Fermentation methods; Mucilage; Saladette; Force.

\section{Resumen}

El tomate tiene una madurez fisiológica desigual del fruto, que es uno de los principales problemas en la producción. Para eliminar el mucílago de la semilla de tomate, se pueden utilizar varios métodos, incluida la fermentación natural. El objetivo de este estudio fue evaluar la calidad de semillas de tomate en diferentes estados de madurez fisiológica de frutos y periodos de fermentación. Se utilizó un diseño completamente al azar en un esquema factorial 2x6. Los 
tratamientos fueron 2 etapas de madurez del fruto a la cosecha: madurez media y madurez completa y seis periodos de fermentación después de la extracción de la semilla: 0, 2, 4, 6, 8 y 10 días. Las variables analizadas fueron: prueba estándar de germinación, emergencia del campo, contenido de humedad y masa seca de la plántula. La etapa de cosecha de tomate de plena madurez del fruto mostró mejores resultados para la calidad de la semilla. El período de fermentación de seis días después de la extracción de la semilla proporcionó mejores resultados para el vigor de la semilla.

Palabras clave: Germinación; Métodos de fermentación; Mucílago; Saladette; Fuerza.

\section{Introdução}

O tomate (Solanum lycopersicon) se destaca devido a sua característica de dupla aptidão, sendo recomendado para o consumo in natura e também para o processamento industrial (Embrapa, 2016). A produção de hortaliças apresenta um grande avanço no agronegócio brasileiro, em função de seus investimentos com pesquisas e inovações tecnológicas em suas principais culturas como o tomate italiano. Dentro da movimentação financeira da cadeia produtiva de hortaliças, o comércio de sementes e mudas de tomate movimentam valores em torno de 94 milhões de dólares (Abcsem, 2017).

O estado Goiás é destaque no Brasil sendo o maior produtor nacional em se tratando de tomate para indústria, e que são destinados para molhos e também extratos, correspondendo a mais de $60 \%$ do total cultivado no Brasil; quanto ao tomate para consumo in natura, a produção é ampla, abrangendo diversas regiões produtoras dentre elas estão São Paulo, Minas Gerais, Goiás e Bahia (Conab, 2019).

O tomate é um fruto climatérico, amadurece rapidamente após a colheita devido aumento da transpiração e da respiração. O processo de maturidade das sementes tem continuidade após sua colheita e é um aspecto vantajoso, pois permite colher os frutos mais precocemente passando por um período de armazenamento ou repouso até que as sementes atinjam seu melhor vigor (Monteiro et al., 2018).

De acordo com Bezerra et al. (2015), a presença da mucilagem na semente pode ser prejudicial à germinação e ao desenvolvimento das plântulas por favorecer a incidência de microrganismos ou conter substâncias inibidoras do metabolismo germinativo, uma vez que, essa mucilagem pode servir como meio de propagação de patógenos.

Devido as sementes de tomate possuírem um envoltório denominado sarcotesta, que pode estabelecer uma barreira à germinação, alguns procedimentos como fermentação natural, processos químicos como ácido clorídrico e mecânicos podem ser utilizados para a retirada da mucilagem, porém, deve garantir sua qualidade fisiológica, onde a sua presença aderida a semente exige um bom beneficiamento para sua retirada (Oliva et al., 2017).

Conforme Borges (2015), a produção de sementes de alta qualidade genética, fisiológica, física e sanitária ainda é um dos principais desafios para a pesquisa e para as empresas produtoras. Dentro desta perspectiva vários aspectos relacionados à produção de sementes das espécies devem ser melhores investigados, dentre eles, os estudos sobre a maturidade e época de colheita, buscando com isso o aprimoramento das tecnologias para a produção de sementes híbridas (Nascimento, 2015).

Devido a necessidade da semente do tomate passar por procedimentos de retirada da mucilagem como a fermentação, e também dos frutos continuarem a sua maturidade pós-colheita, são poucos os estudos relacionados a estes aspectos. Diante do exposto objetivou-se avaliar a qualidade de sementes de tomate sob diferentes estágios de maturidade fisiológica de frutos e de períodos de fermentação das sementes.

\section{Metodologia}

O presente trabalho foi realizado no laboratório de análise de sementes (LAS) do Instituto Federal Goiano - Campus Ceres, no primeiro semestre de 2021. As sementes de tomate estudadas foram do grupo Saladete (Solanum lycopersicum cv 'Roma'), que foi adquirida da Fazenda Mocambo, no município de Gameleira, Goiás. 
No laboratório os frutos de tomate foram separados em dois grupos de acordo com seu estágio de maturidade fisiológica estabelecido: médio e total. Em seguida, os frutos ficaram em repouso por 24 horas na temperatura de $25^{\circ} \mathrm{C} \mathrm{em}$ bancada do laboratório.

Foi utilizado o delineamento inteiramente casualizado (DIC) em esquema fatorial de 2 × 6 , sendo dois estágios de maturidade fisiológica de frutos e seis períodos de fermentação das sementes e quatro repetições. Os tratamentos foram: 2 estágios de maturidade de frutos na colheita (maturidade média de frutos com a coloração matiz $2.5 \mathrm{Y}$ 6/8 olive yellow e maturidade total de frutos com a coloração matiz 10R 4/8 red) e seis períodos de fermentação das sementes $(0,2,4,6,8$ e 10 dias após a extração). As cores dos frutos de tomate foram definidas utilizando-se a carta de Munsell (Munsell, 1975).

Após a extração as sementes foram colocadas para fermentação em um recipiente de isopor (tipo marmitex). As sementes passaram pelo processo de fermentação natural com temperatura de $25^{\circ} \mathrm{C}$ no laboratório utilizando-se somente o líquido do fruto. Depois de cada período de fermentação as sementes foram lavadas em água corrente em uma peneira de malha fina para retirada da mucilagem, e por fim, foi feita a pré-secagem por quatro dias sobre papel toalha em bancada no laboratório.

As sementes secas de acordo com cada período de fermentação foram colocadas em saquinhos de papel, armazenadas em refrigerador e feitas as seguintes análises: Teste Padrão de Germinação (TPG), Envelhecimento Acelerado (EA), Grau de Umidade (GU) e Massa Seca de Plântulas (MSP).

O TPG foi realizado de acordo com Brasil (2009), com 400 sementes, distribuídas sobre duas folhas de papel mata borrão umedecidas com água (2,5 vezes o peso do papel seco), em caixas tipo gerbox com medidas de 11x11x3,5 cm. As caixas foram colocadas em germinador tipo B.O.D (Demanda Bioquímica de Oxigênio) a $25^{\circ} \mathrm{C}$. As avaliações foram realizadas no sétimo e no $14^{\circ}$ dia. O EA foi realizado com 400 sementes e foram distribuídas uniformemente sobre tela acoplada à caixa gerbox, com $40 \mathrm{ml}$ de água destilada (Marcos Filho, 1999). As caixas permaneceram cobertas e mantidas em câmara tipo B.O.D a $41^{\circ} \mathrm{C}$ por 72 horas. Logo em seguida foi montado o TPG.

O GU das sementes foi determinado conforme metodologia de Brasil (2009), pelo método da secagem em estufa a $105 \pm 3^{\circ} \mathrm{C}$, por 24 horas, utilizando-se quatro repetições de 25 sementes. A MSP foi determinada após a determinação da emergência em campo, em seguida foi realizada a secagem na estufa a $105 \pm 3^{\circ} \mathrm{C}$ por $24 \mathrm{~h}$ (BRASIL, 2009), onde foi feita a pesagem em balança de precisão para sua determinação.

Os dados foram submetidos a análise de variância (ANOVA) e as médias dos tratamentos para a maturidade de frutos foram submetidas ao teste de Tukey a nível de 5\% de significância; para os períodos de fermentação foram realizadas análise de regressão. Os dados foram submetidos ao programa computacional Sisvar 4.3 para as análises estatísticas.

\section{Resultados e Discussão}

$\mathrm{Na}$ (Tabela 1), nota-se que as variáveis TPG, EA, GU e MSP foram influenciadas significativamente pelos períodos de fermentação após a extração das sementes. Para os estágios de maturidade fisiológica houve diferença estatística para a MSP, sendo esta também, influenciada significativamente pela interação entre estágios de maturidade fisiológica de frutos e períodos de fermentação (Tabela 1). 
Tabela 1. Resultado da análise de variância para Teste Padrão de Germinação (TPG), envelhecimento acelerado (EA), grau de umidade (GU) e massa seca de plântulas (MSP). Ceres, GO. 2021.

\begin{tabular}{cccccc}
\hline FV & GL & TPG & EA & GU & MSP \\
\hline Maturação & 1 & $4,68^{\text {ns }}$ & $133,33^{\text {ns }}$ & $12,12^{\text {ns }}$ & $361765,05^{* *}$ \\
Fermentação & 5 & $480,53^{* *}$ & $1258,13^{* *}$ & $32,06^{* *}$ & $16634,02^{*}$ \\
Int. M x F & 5 & $21,13^{\text {ns }}$ & $26,13^{\text {ns }}$ & $4,23^{\text {ns }}$ & $28657,22^{*}$ \\
Erro & 36 & 11,06 & 41,77 & 3,16 & 3870,72 \\
\hline CV $(\%)$ & & 4,07 & 8,47 & 14,67 & 16,09 \\
\hline
\end{tabular}

FV - Fonte de variação; GL - grau de liberdade; ** e $\mathrm{e}^{*}$ - significativo a 1 e $5 \%$ de probabilidade, respectivamente; ns - não significativo a 5\% de probabilidade pelo teste F; CV - coeficiente de variação. Fonte: Autores.

Para a variável TPG (Figura 1), nos diferentes períodos de fermentação, o modelo de regressão ajustado foi o quadrático. Com o período de sete dias de fermentação após a extração das sementes obteve-se $85 \%$ de germinação. $\mathrm{O}$ resultado para o TPG está de acordo Brasil (2019), onde exige que para um lote ser considerado semente a germinação deve ser no mínimo de $80 \%$. Santos et al. (2017), ao estudarem germinação de genótipos de tomate sob diferentes métodos de extração de semente, notaram que sementes até o $7^{\circ}$ dia de fermentação tiveram em média $85 \%$ para germinação.

Figura 1. Teste padrão de germinação de sementes de tomate cv. Roma submetidas a períodos de fermentação após a extração. Ceres, GO. 2021.

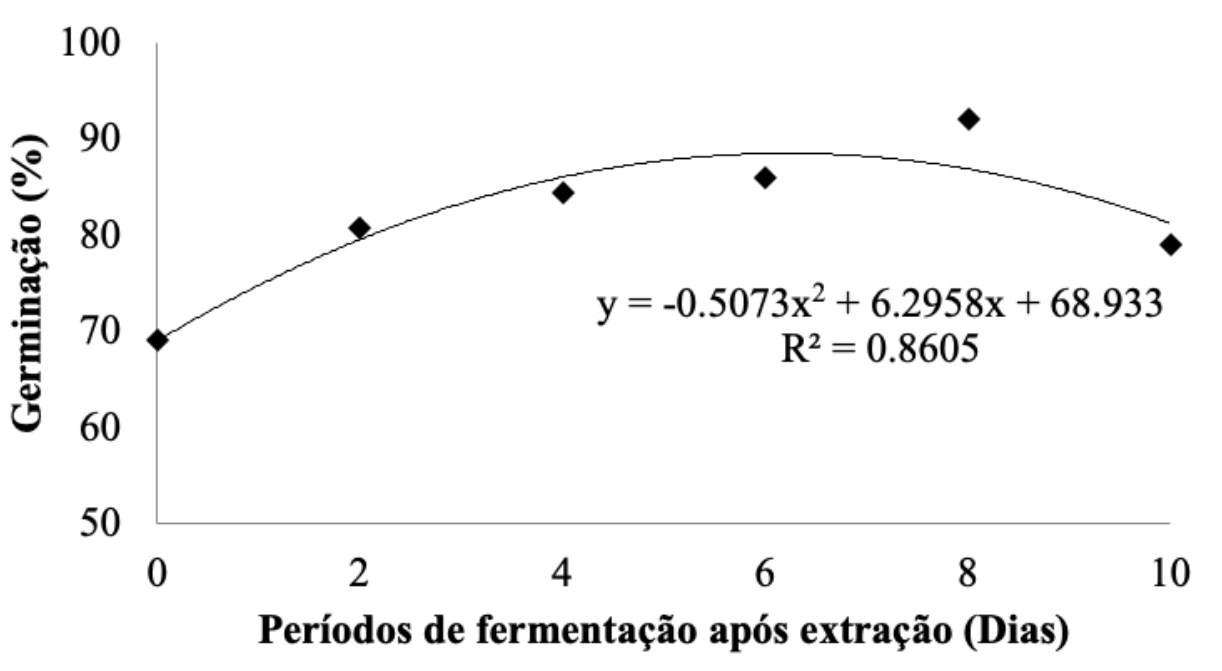

Fonte: Autores.

O EA (Figura 2), nos diferentes períodos de fermentação, o modelo de regressão ajustado foi o quadrático. Com seis dias após a extração e fermentação das sementes obteve-se $83 \%$ quando foi feito o teste de envelhecimento acelerado. Esse teste tem como objetivo verificar a taxa de germinação das sementes após passar por um estresse térmico junto a uma concentração salina. Segundo Pereira et al., (2017), a atividade dos microrganismos como bolores, do grupo dos ascomicetos presentes no líquido da fermentação pode facilitar a degradação da sarcostesta presente nas sementes e promover a 
germinação. Esses resultados obtidos da germinação para o teste de envelhecimento acelerado indica que esse lote de sementes pode tolerar oarmazenamento sem prejudicar a qualidade e vigor.

Figura 2. Envelhecimento acelerado de sementes de tomate cv. Roma submetidas a períodos de fermentação após a extração.Ceres, GO. 2021.

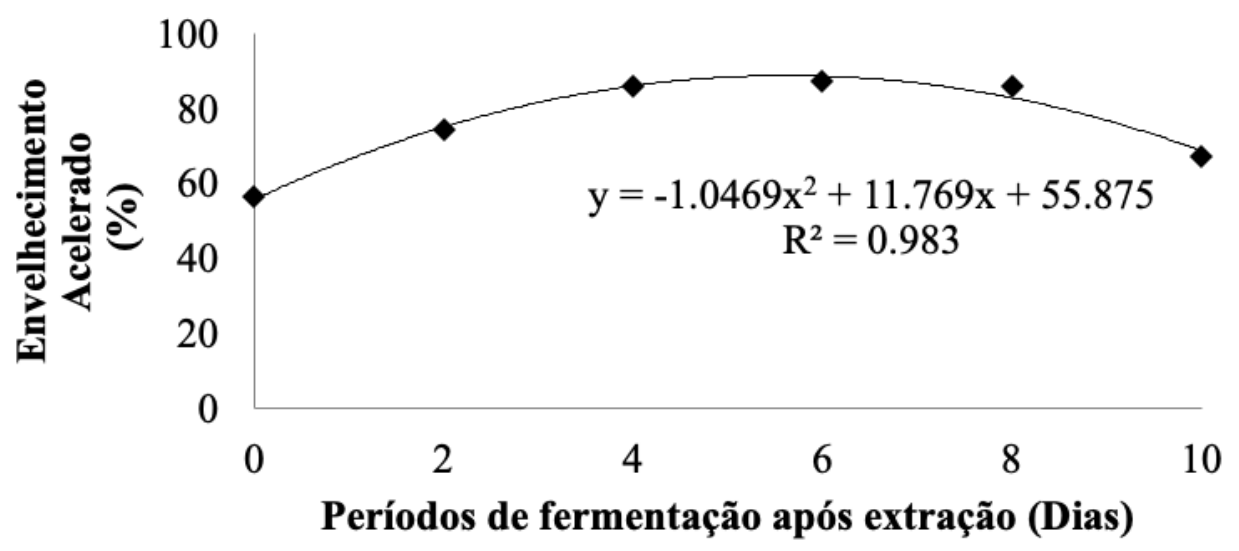

Fonte: Autores.

Observa-se na (Figura 3), que houve uma resposta linear crescente ao período de fermentação após a extração das sementes de tomate para a variável Grau de Umidade. Para o maior tratamento obteve 14\% de umidade. Aumento no grau de umidade de sementes sobre período de fermentação também foi constado por Vidigal et al. (2006), ao avaliarem a qualidade de sementes de tomate em função da idade e armazenamento após a extração da semente. Esse resultado é devido a absorção de água pela semente que ficou maior tempo em contato com o líquido do fruto.

Figura 3. Grau de umidade de sementes de tomate cv. Roma submetidas a períodos de fermentação após a extração. Ceres, GO. 2021.

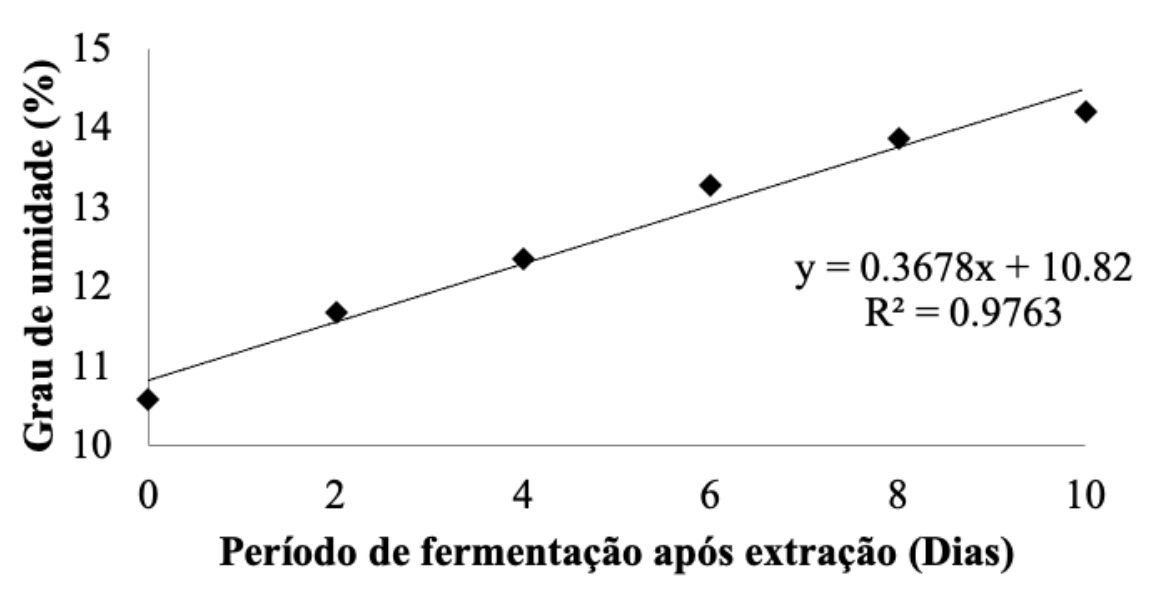

Fonte: Autores.

Para massa seca de plântulas ambos os estágios de maturidade fisiológica de frutos de tomate proporcionaram um crescimento constante até aos oito dias após a fermentação das sementes (Figura 4). A MSP foi maior na maturidade fisiológica total de frutos quando comparada com os da maturidade média de frutos no $7^{\circ}$ dia. Esses resultados podem ser 
justificados pela semente ser um dreno que quando recebe conteúdo da fotossíntese resulta no aumento de matéria seca (MARTINELLI et al, 2014).

Figura 4. Massa seca de plântulas de tomate cv. Roma submetidas a períodos de fermentação após a extração. Ceres, GO.2021.

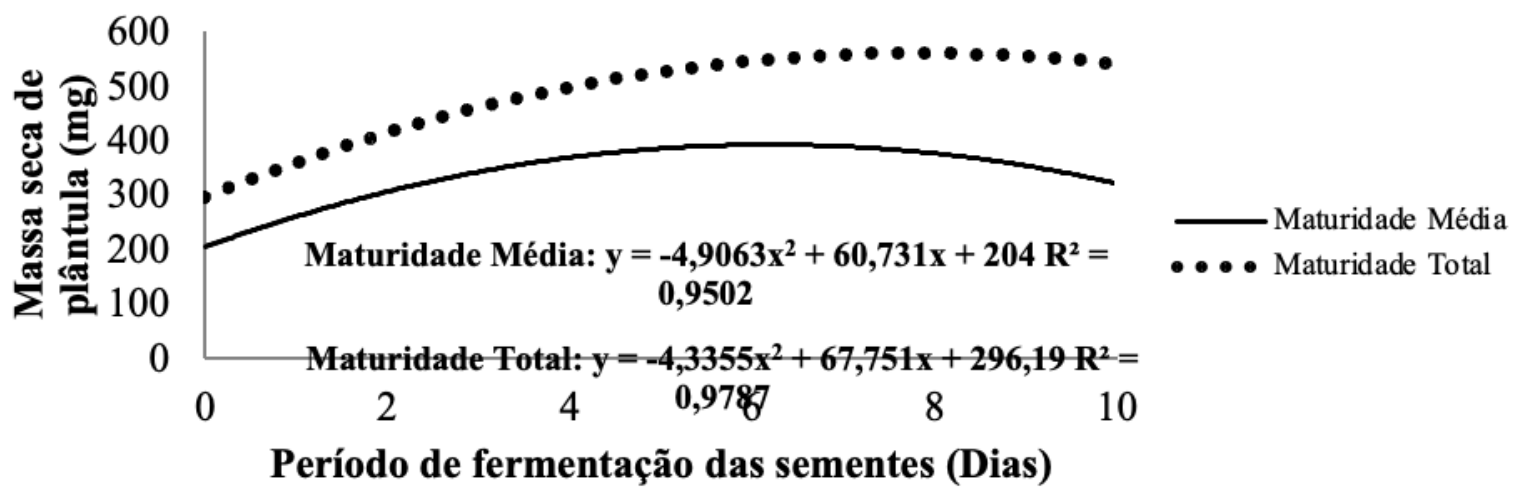

Fonte: Autores.

De acordo com Marcos Filho (2005), o teor de água das sementes mantém-se alto, decrescendo lentamente à medida que a água vai sendo substituída pelas reservas sintetizadas. O resultado obtido para a MSP do presente trabalho para a maturidade total de frutos de tomate proporcionou maior germinação em campo, como apresentado anteriormente.

\section{Conclusão}

O estágio de colheita de tomate de maturidade total de frutos apresentou melhores resultados para a qualidade de sementes.

O período de fermentação com seis dias após a extração das sementes proporcionou melhores resultados para o vigor das sementes.

\section{Referências}

ABCSEM - Associação Brasileira do Comércio de Sementes e Mudas (2017). Mapeamento e quantificação da cadeia produtiva de hortaliç/as. Brasília, 79 p. Association of Official Seed Analysts AOSA (2002). Seed Vigor Testing Handbook. AOSA, Lincoln, NE, USA. Contribuition, $32,2002$.

Bezerra, A. K. D., Silva, G. Z., Nascimento, L. C., Bruno, R. L. A. (2015). Extração da mucilagem em sementes de Genipa americana L. visando o potencial fisiológico. Revista Ciência Agronômica, 46(4), 786-791.

Borges, E. E. L. (2015). Alterações fisiológicas e atividade enzimática em sementes armazenadas de Melanoxylon brauna Schott. Cerne, 21(1), 75-81.

Brasil. (2009). Ministério da Agricultura, Pecuária e Abastecimento. Regras para análise de sementes / Ministério da Agricultura, Pecuária e Abastecimento. Secretaria de Defesa Agropecuária. - Brasília: Mapa/ ACS. 399.

Brasil. (2019). Ministério da Agricultura, Pecuária e Abastecimento. Instrução Normativa Nº 42, DE 17 DE SETEMBRO DE 2019. Diário oficial da União Seção 1. - Brasília: No 182 .

Conab - Companhia nacional de abastecimento. Análise dos Indicadores da Produção e Comercialização no Mercado Mundial, Brasileiro e Catarinense (2019). safra 2017/18 - Brasília, 19. https://www.conab.gov.br/ sc.sureg@ conab.gov.br.

Embrapa - Empresa Brasileira de Pesquisa Agropecuária (2018). Soluções tecnológicas: Tomate BRS Nagai. Marcos Filho, J. (2005). Fisiologia de sementes de plantas cultivadas. Piracicaba: Fealq, 495.

Marcos Filho, J. (2005). Fisiologia de sementes de plantas cultivadas. Piracicaba: Fealq, 495.

Marcos Filho, J. (1999). Teste de envelhecimento acelerado. In: Vigor de sementes: conceitos e testes. Londrina: ABRATES, cap.3, 1-24. 
Research, Society and Development, v. 11, n. 3, e18811325703, 2022

(CC BY 4.0) | ISSN 2525-3409 | DOI: http://dx.doi.org/10.33448/rsd-v11i3.25703

Martinelli S. A.., Martins, C. C., Castro, M. M., Nakagawa, J., Cavariani, C. (2004). Avaliação do vigor de sementes peliculizadas de tomate. Revista Brasileira de Sementes, 26(2), 1-6.

Monteiro, S. S., Silva, E. A., Martins, L. P. (2018). Maturação fisiológica de tomate cereja. Revista Brasileira de Agrotecnologia, 8(3), 05-09.

Munsell soil color company, Munsell soil color chats, Munsell color. (1950). Macbeth Division of Kollmorgen Corporation, Baltimore, Maryland, USA, revised 1975 .

Nascimento, W.M. (2015). Condicionamento osmótico de sementes de hortaliças visando a germinação em condições de temperaturas baixas. Horticultura Brasileira, 23(2), 211-214.

Oliva, F. A., Pocaia, A. P., Lima, B. C., Baldoto, P. V., Fernandes, D., Carvalho, L. O., Amin, M. V. (2017). Extração de sementes de tomate sem fermentação. Colloquium Agrariae, 13(7), 82-87.

Santos, P. L. F., Silva, O. N. M., Paixão, A. P., Castilho, R. M. M. (2017). Germinação e desenvolvimento de mudas do tomate cereja em diferentes substratos Revista Tecnologia e Ciência Agropecuária, João Pessoa, 11(5), 41 - 45.

Vidigal, D. S., Dias, D. C. F. S., Naveira, D. S. P. C., Rocha, F. B., Bhering, M. C. (2006). Qualidade fisiológica de sementes de tomate em função da idade e do armazenamento pós-colheita dos frutos. Revista Brasileira de Sementes, São Paulo, 28(3), 87-93. 